\title{
Discursos literarios en Costa Rica
}

\author{
Carlos Pacheco Solórzano \\ Licenciado en Lingüística y Literatura (UNA) y Máster en Literatura Latinoamericana (UCR). Profesor del Colegio Méxi- \\ co y Tutor de la Cátedra de Lengua y Literatura (UNED). Correo electrónico: carlospacheco2558@yahoo.com
}

Recibido: 26 de febrero 2013 • Aprobado: 27 de junio 2013

\section{RESUMEN}

El título del presente artículo es pretencioso, "Discursos literarios en Costa Rica". Sin embargo, se trata de mostrar que hay referentes históricos y literarios que son consulta obligada para las investigaciones en el campo de la literatura como Historia de la literatura costarricense (Abelardo Bonilla); el papel de la imprenta en Costa Rica, el Archivo Nacional y el texto del maestro Álvaro Quesada Soto Uno y los otros. Así, esta primera parte se subtitula como Tradición histórica $y$ literaria. La segunda parte se ha titulado Espejo de las vanguardias, que da cuenta de los principales movimientos vanguardistas de Europa y de América Latina y su influencia en el discurso literario costarricense. Un tercer subtítulo, Renovación discursiva, presenta una heterogeneidad de voces literarias posvanguardista e incorporación de la literatura gótica y de ciencia ficción en la producción literaria costarricense de nuestros días.

Palabras clave: discurso, literatura, vanguardismo, gótica y ciencia ficción.

\section{ABSTRACT}

The title of this article is pretentious "Discursos Literarios en Costa Rica". However, the point of it is to show that there are historical and literary references that are obligatory reference for research in the field of literature as "Historia de la literature costarricense" (Abelardo Bonilla), the role of the printing house in Costa Rica, the National Archives and the text from Alvaro Quesada Soto (Uno y los otros). Thus, this first part is under the topic of Historical and Literary tradition. The second part is entitled Avant-garde Mirror, which accounts for the major avant-garde movements in Europe and Latin America, and its influence on Costa Rican literary discourse. A third subtitle, Renewal Discursive, heterogeneity presents literary voices from the subsequent avant-garde movement and the incorporation of Gothic literature and science fiction in Costa Rican literary production today.

Keywords: Speech, literature, avant garde, Gothic and science fiction.

En la primera parte de este artículo, se pretende subrayar referentes históricos y literarios que han pasado desapercibidos o subvalorados por la crítica literaria, como la magnífica obra de Abelardo Bonilla y el aporte cultural que significó la llegada de la imprenta al país o las profundas huellas de la vida nacional que destilan en escrituras, remates e hipotecas y que están resguardadas en el Archivo Nacional. En una segunda parte, se alude a las vanguardias europeas y latinoamericanas que influyeron en el discurso literario de los escritores nacionales y finalmente, 
las últimas tendencias literarias que son híbridos vanguardistas teñidos de discretas voces góticas y de ciencia ficción.

\section{Tradición histórica y literaria}

Toda referencia a la literatura costarricense requiere de la consulta obligada de la obra de Abelardo Bonilla: Historia de la literatura costarricense (1957). Se trata de un extraordinario legado investigativo -histórico, económico, político y literario- que da cuenta de la "Época colonial", "Época de formación y consolidación del Estado", "Época realista" y "Época contemporánea" (Idem.32). A él se debe el hallazgo de la primera poesía costarricense de la colonia, se trata de las "Coplas" de Domingo Jiménez, escritas en 1574 (Id. 48). Casi tres siglos después, el hecho más importante es la llegada al país de la imprenta en 1830 (Id. 68-69) por lo tanto, la divulgación de textos educativos y la publicación de la primera Ley de Instrucción Pública el 4 de mayo de 1832 por el nicaragüense Bachiller Francisco Osejo. Posteriormente, otra fuente casi inexplorada por la crítica literaria es la creación del Registro Público o Registro Nacional (1867) que da cuenta de la inscripción de propiedades e hipotecas (2011: Año 6 No. 4: 3)

En esta misma época, ya se cultiva y exporta a Inglaterra el "grano de oro" y según Álvaro Quesada (2002), "En las tres últimas décadas del siglo XIX la oligarquía cafetalera consolida su posición como clase dominante en el interior del país e intenta consolidar también, bajo su égi$\mathrm{da}$, un estado nacional con sus correspondientes aparatos ideológicos, uniformados bajo el signo del liberalismo político y del positivismo filosófico". (p.23) Con este marco cultural, el discurso nacionalista se perfila como esa comunidad imaginada y transformada en elementos materiales y espirituales que le dan vida a ese lugar común: "la patria"que sintetiza con toda la carga ideológica, el amor, el gozo de "lo nuestro" que se exhibe con orgullo frente al otro.

Precisamente, para Alexander Jiménez (2008: 85-86), la invención de la Nación costarricense es parte del modelo liberal que responde a ese discurso de homogeneidad racial de un país blanco, igualitario y otros estereotipos que privilegian al Valle Central y excluyen la Zona Atlántica y el Pacífico. Los rasgos que enuncia Alexander Jiménez se cimentan en la economía agroexportadora del monopolio del café. Por una parte, hay una imagen del país que promociona la oligarquía hacia el exterior con sus beneficios y privilegios; por otro lado, hacia el interior del país, las pérdidas, la exclusión social y política, se multiplican. De acuerdo con Álvaro Quesada Soto (2002), "Mientras los políticos se encargan de montar el nuevo Estado liberal, con sus leyes, códigos e instituciones, los otros intelectuales se encargan de elaborar la nueva mitología oficial costarricense, con sus héroes, gestas y monumentos; con su historia, su cultura y su literatura nacional". (pp. 34-35)

Los intelectuales a los que alude Quesada Soto conforman El Olimpo, (Gagini, Magón, Aquileo Echeverría, Fernández Guardia, entre otros) y sus textos responden a esa literatura del Valle Central con exclusión de las zonas rurales como Guanacaste, Limón o Puntarenas y ni qué decir de las zonas indígenas totalmente invisibilizadas. Si se quiere, hay un discurso literario simétrico con la visión política e ideológica de la oligarquía cafetalera que se unifica con la dinámica económica de la modernidad.

Así, la producción literaria de esta generación tiene como referente el discurso de corte realista-costumbrista (Magón) en el cual se viene a idealizar la imagen del campesino: ese labriego sencillo que se dobla sobre el surco, el de la carreta y el "chonete". Con esta propuesta ideológica se construye el discurso sobre la identidad nacional y da paso a la "polémica sobre nacionalismo literario" (1894-1902), primera discusión teórica-literaria que protagonizan Carlos Gagini, Ricardo Fernández Guardia y otros. El primero da cuenta de la necesidad de hacer literatura partiendo del contexto nacional, de su gente e idealizando el terruño. El segundo pone en tela de duda que exista material necesario para hacer literatura de corte universal: "Mi humilde opinión es que nuestro pueblo es sandio, sin gracia 
alguna, desprovisto de toda poesía y originalidad que puedan dar nacimiento siquiera a una pobre sensación artística" (El Heraldo, 1894).

Asimismo, en el primero sobresale la imagen de una sociedad paradisíaca, sencilla, natural, subordinada a los designios de la voz oficial y legitimada por la costumbre y la tradición (Gagini). El segundo discurso tiene que ver con la modernidad, con una producción simbólica de trascendencia y que se asemeje al modelo europeo; afán cosmopolita de Fernández Guardia que aspira a una innovación en las relaciones de producción literaria y mercantil. Sin embargo, para Álvaro Quesada, en Costa Rica hay una simbiosis literaria, una convergencia de tendencia literarias que se perfilan en los textos: el romanticismo, realismo, costumbrismo (o regionalismos), naturalismo o modernismo. Esta relación de movimientos literarios aunados a los discursos que se permean es lo que llama Álvaro Quesada: "eclecticismo amorfo...sus textos parecen hechos de varios elementos discursivos heterogéneos que no se integran fácilmente" (Id. 39).

La hibridez de movimientos literarios que apunta Quesada Soto, en las obras de los autores nacionales, responde a esa búsqueda y definiciones del discurso literario que no son exclusivos del Costa Rica, sino de América Latina y en obras como Amalia (1851-1855) de José Mármol o María (1867) de Jorge Isaacs. Justamente, El Moto (1900) de Joaquín García Monge, muestra esa convergencia de corrientes literarias: el amor frustrado de José Blas (romanticismo), los rezos, coplas, diezmos (regionalismo), la exclusión social (realismo)... Si bien es cierto que el protagonista termina derrotado por el poder económico-patriarcal, no sucumbe a la voluntad del gamonal ni acepta la resignación lisonjera del padre Yanuario por el contrario, rompe con esa estructura de clase y cuestiona con sus actos la forma de ejercer el poder: "La resistencia contra el poder oligárquico-patriarcal, sus representaciones simbólicas y literarias, se inicia en Costa Rica con este pequeño texto adolescente, publicado al comenzar el siglo XX" (Id. 117).
Mientras la oligarquía nacional se ajustaba el ropaje moderno-liberal para darle la bienvenida al nuevo siglo XX, acontecimientos históricos estremecían el planeta. La Primera Guerra Mundial (1914-1918) en la cual participarían todas las potencias mundiales, desgarrarían en forma brutal al ser humano; la Revolución Rusa (1918) con el salto del proletariado al poder y una estela impresionante de sacrificios; la Revolución Mexicana (1911-1924) y el sueño inconcluso de Emiliano Zapata de tierra para todos; la heroica resistencia de Augusto César Sandino contra la invasión de los Estados Unidos a Nicaragua. Alguno de estos acontecimientos van encontrar receptividad en el Repertorio Americano (1919-1958), revista monumental en el contexto de la época, abierta a la producción literaria y a los acontecimientos históricos y sociales, fundada y editada por Joaquín García Monge: "Los grandes movimientos sociales latinoamericanos, la revolución mexicana, (...) las reformas universitarias en Argentina, la resistencia de Sandino a la invasión estadounidense en Nicaragua, la masacre de campesinos indígenas en El Salvador, la lucha contra las dictaduras y las nuevas variantes del antiimperialismo" (Id.134)

\section{Espejo de las vanguardias}

Otro gran acontecimiento para la literatura del siglo XX fue el movimiento vanguardistas europeo. Estas manifestaciones vanguardistas recogen los avances científicos y técnicos, los aeroplanos y los trasatlánticos, la luz eléctrica y el subconsciente, y un profundo malestar por el pasado erigido como un museo de artefactos olvidados (Enciclopedia del Estudiante, 2005), El Jaúl (1937), Alvarado (2009). El cubismo (1906) del pintor español Pablo Picasso -«Pablo Diego José Francisco de Paula Juan Nepomuceno María de los Remedios Crispiniano de la Santísima Trinidad Ruiz Picasso»- es una tendencia que se expresa a través "líneas geométricas entrecruzadas, que aluden a la multiplicidad de percepciones físicas y mentales que se pueden tener de un objeto, cuando es considerado en sí mismo" (Idem. p.274). El Futurismo del poeta italiano 
Filippo Tomaso Marinetti (1909) es una exaltación al progreso, a lo técnico, científico, a la rapidez de la comunicación "clamaba por un mundo nuevo. Además, apelaba a la agresividad juvenil como instrumento para acabar con las tradiciones corrompidas, a la violencia y a la guerra como medio de regeneración" (Id., p.276). El Dadaísmo (1916) del poeta rumano Tristan Tzara surge en plena Guerra Mundial:

Los dos pilares del dadaísmo son, por una parte, el escándalo, la polémica y la provocación como revulsivo de todo juicio intelectual o estético preconcebido; y, por otra parte, la reivindicación del azar y la dimensión irracional de la condición humana, como componente esencial de la creación, que se concibe como un descubrimiento, una relación sorprendente que antes no existía. (Id.p.280).

El surrealismo (1924) del escritor francés André Breton que propone el automatismo de la escritura impulsado por el instinto:

Las dos claves fundamentales sobre las que se asientan las obras artísticas nacidas del surrealismo son... la negación de la moral tradicional, especialmente en lo que se refiere al sexo y a la violencia,... la exploración de las más reprimidas pulsiones eróticas constituye una forma de liberación; la reivindicación de la dimensión irracional e instintiva de la condición humana, herencia del dadaísmo, que altera de forma inesperada y sorprendente la aparente lógica por la que fluye el mundo. (Id. p.282)

El vigor discursivo que exhalaron los movimientos vanguardistas correspondió a una fuerza telúrica y cósmica que sacudieron los círculos literarios latinoamericanos. Unos abjuraron del discurso fundacional bucólico y experimentaron formas irreverentes (rompimiento de la sintaxis, inversión de los elementos morfológicos, ruptura del significado y prioridad del significante...). Otros combinaron el lenguaje vernáculo con las imágenes que ronda el subconsciente y el universo onírico. Sin embargo, todos coincidieron en la necesidad de renovar las imágenes modernistas, realistas y románticas; están de acuerdo en lanzarse sin paracaídas hacia el infinito de la creación verbal; rechazan los lugares comunes de la cultura burguesa y sus seductores refinamientos estéticos. "La avanzada" artística explora los dogmas con el existencialismo, la moral con las pulsiones eróticas freudianas y las tendencias literarias más connotadas en América Latina fijan un rumbo hacia todos los espacios posibles: El Creacionismo del chileno Vicente Huidobro (1910), el $U l$ traísmo argentino de Jorge Luis Borges (1921), El Movimiento Antropófago de Brasil (1922), El Estridentismo mexicano (1921), La Vanguardia peruana (1922), Chile Grupo Montparnasse (1922), El Diepalismo puertorriqueño de Diego Padró y Luis Palés Matos (1921), Vanguardia de Cuba (1927), Vanguardia venezolana (1925), Vanguardia de Ecuador (1926)

Especial mención merece El Movimiento de Vanguardia de Nicaragua, único movimiento vanguardista en Centro América y la última corriente rupturista en América Latina, según Jorge Schwartz (1991). La vanguardia nicaragüense aparece a finales de los años veinte, abjuran del modernismo dariano, de su cosmopolitismo y temas clásicos griegos y latinos, su renovación estética y musical, su exotismo y culto formal preciosista, su musicalidad sensual y su influencia simbolista y parnasiana. Los poetas vuelven los ojos hacia la cotidianidad nicaragüense sacudida por la invasión de Estados Unidos y la lucha de Sandino en las montañas. José Coronel Urtecho (1906-1994), uno de los fundadores de la vanguardia nicaragüense, despliega su Oda a Rubén Dario, en la cual se conjuga la sátira y lenguaje vernáculo renovado, y marca la rebelión estética contra el maestro del azul.

¿Y cómo se manifiesta el vanguardismo en Costa Rica? Para Quesada Soto (2002), hay una serie de escritores, pintores, escultores que encarnan y comparten las ideas vanguardistas europeas y latinoamericanas: "Juan Rafael Chacón (1894-1982), Teodorico Quirós (1897-1975), Fausto Pacheco (1899-1966), Luisa González de Sáenz (1899-1982), Juan Manuel Sánchez (19071990), Manuel de la Cruz González (1909-1986), Francisco Amighetti, Carlos Salazar Herrera”. (p.153). Sin embargo, no hay duda que la referencia más destacada es la del poeta, pintor, escritor, 
escultor y periodista Max Jiménez que sacude, con sus obras, el medio artístico nacional de la época; ignorado por unos y admirado por otros es artífice de su propia cultura que forja en sus viajes por Europa, Estados Unidos y Latinoamericana. Su última novela El Jaúl (1937), publicada en Chile, es una desmitificación del labriego sencillo, del campesino idealizado, noble, trabajador, pacífico, doblado en los surcos de la tierra, amoroso con su familia y abnegado:

La familia patriarcal, núcleo y santuario de las buenas costumbres, de las leyes morales y religiosas, aparece en El Jaúl como un infierno de promiscuidad, terror y violencia, enardecidos por el alcoholismo, el machismo y una sexualidad instintiva, que rige las relaciones del marido con la esposa y los hijos, de la madre con sus hijas e hijos, de los hombres con los otros hombres y de las mujeres con las demás mujeres. (p.200).

En este tránsito vanguardista y postvanguardista (década del 30 al 50) se inscribe una nueva lectura de la realidad y sus acontecimientos históricos ineludibles: la Guerra Civil Española, la Segunda Guerra Mundial, las dictaduras latinoamericanas y profundos cambios a nivel nacional: el Código de Trabajo, fruto de esa exótica alianza entre el Partido Comunista, la Iglesia Católica y un sector de la clase dominante local- la Caja Costarricense del Seguro Social (CCSS); la creación de la Universidad de Costa Rica (UCR); la Segunda República y la naciente industrialización nacional. Carlos Cortés (2003), Rodrigo Soto (2009) y Álvaro Quesada Soto (2010) coinciden en manifestar que la novela realista predominará durante la mitad del siglo XX con sus temas sociales y la incorporación de sujetos marginales (Carlos Luis Fallas, Carmen Lyra, Joaquín Gutiérrez, Fabián Dobles y muchos más): “(...)la novela de los autores de esta promoción se abre a nuevas regiones geográficas (las costas del Pacífico y del Caribe, Talamanca, Guanacaste) y a la incorporación de grupos sociales marginados o excluidos en papeles protagónicos (campesinos, clases medias, trabajadores urbanos y bananeros, mujeres, negros, indios)". (p.78) Sin obstante, este proceso de producción simbólica pronto incorporará otras técnicas narrativas como el caso de Yolanda Oreamuno, -La ruta de su evasión-, merced a la influencia de escritores de otras latitudes.

\section{Renovación discursiva}

Para la década del sesenta y hasta finales del siglo XX, un relevo de nuevos escritores dará un impulso extraordinario a la escritura nacional. Ahora, con la influencia de poderosas escrituras latinoamericanas (Borges, Sábato, Galeano, Benedetti, Onetti, Cortázar, Neruda, Vargas Llosa, Roa Bastos, Paz, Fuentes, Carpentier, Lezama Lima, Martí, Guillén, Belli y tantos otros y otras); de Estados Unidos (Faulkner, Hemingway, Dos Passos, Steinbeck Poe y más) y Europa (Graham Green, Goytisolo, Marsé, Eco, Saramago, Lorca, Alberti, Cela, entre otros) Se abandona el litoral, las zonas rurales y se incursiona en la meseta central, es decir, San José. El tema del espacio urbano será todo un proceso de experimentación en la producción literaria (narrativa, lírica, teatro, ensayo): desplazamiento de la narración, ruptura del tiempo, polifonía de personajes, redefinición de espacios, juego de intertextualidad, juegos semánticos y de sintaxis.

A esta apropiación de técnicas literarias se le agrega la heterogeneidad que representan las ciudades o, como lo llama Oscar Alvarado (2009), el "laberinto urbano o cosmos urbano", toda una imagen literaria que devela el encuentro y desencuentro de personalidades en conflicto; diversos discursos que se alternan con temas y actores sociales:

El laberinto en el cual se ha convertido la sociedad, más exactamente en las grandes concentraciones urbanas, donde confluyen unos y otros, y que caracteriza la apropiación no solo de lo urbano, sino de los sujetos mismos, víctimas de un entorno en donde la diferencia se torna la característica predominante hace que el caos se manifieste como un elemento que no ha de permanecer ajeno en esta producción. (p.169)

En este laberinto urbano se presentan diversas contradicciones que no son ajenas a la producción literaria: "El monopolio del poder, la 
riqueza, el cinismo, la corrupción y la impunidad de los de arriba, contrasta con el sentimiento de deterioro, malestar, impotencia y enajenación de los de abajo" (Quesada, 2010, p.128). Este sentimiento de frustración permea en la visión de Carlos Cortés (2003, p.61): “'Somos una sociedad 'honesta y trabajadora' -labriegos sencillos etcétera- o una sociedad corrupta? ¿Una sociedad que se plantea y problematiza sus errores o una sociedad hipócrita, introvertida, autoritarias, racista, intolerante y conformista?" Esta imagen ambivalente entre la producción simbólica y realidad también tiene resonancia en Rodrigo Soto (2009:101), pero con la firme convicción de "mantener la llama viva" la escritura.

Esa "llama viva", a finales del siglo XX y principios del XXI, se multiplica en los discursos plurales y autores, es decir, la producción literaria costarricense alcanza dimensiones trascendentales. Unos se inscriben en un pasado reciente del conflicto centroamericano: Te llevaré en mis ojos, Rodolfo Arias; Los ojos del antifaz, Adriano Corrales; Cruz de olvido, Carlos Cortés. Otros indagan sobre las voces desgarradas del espacio urbano: Cierto azul, Los Peor, Única mirando al mar, Fernando Contreras; Candelaria del azar, Tatiana Lobo) y de nuevo al Atlántico: Limón Reggae, Ana Cristina Rossi, e indiscutiblemente la voz emblemática de Quince Duncan que reivindica la escritura del negro, de su exclusión, su voz olvidada y ahora reivindicada en toda su obra. Aquellos exploran la polifonía de voces (ensayistas, narradores o poetas): Alfonso Peña, Dorelia Barahona, Guillermo Fernández, Ana Istarú, José Ricardo Chaves, Alexander Obando, Yadira Calvo, Hugo Rivas, Linda Berron, Rodrigo Soto, Osvaldo Sauma, Carlos Francisco Monge, Lil Picado, Mía Gallegos, José María Zonta, Jorge Arroyo, Alexander Jiménez, Rafael Ángel Herra, Alfonso Chase, Gerardo César Hurtado, José León Sánchez, Carlos Calero, Mainor González, Alfredo Trejos, Martín Campos, Ronald Bonilla, Alberto Fonseca, Carlos Villalobos y muchísimos más.

En el centro de una voracidad de tratados internacionales, capitales golondrinas, sumisión absoluta de gobiernos de alquiler por servirles a las transnacionales, de la destrucción ecológica, del crimen organizado en todas sus facetas y un creciente desencanto por la política local, se manifiestan dos abordajes dinámicos en la producción simbólica: la literatura gótica y la literatura de ciencia "ficción". ¿Y estas preferencias? ¿Qué sucede con estas temáticas? ¿Último grito de la moda literaria o es una postmodernidad hecha de retazos que va hacia todos los lugares en un eterno retorno? Pero mientras flotan las interrogantes, abramos un paréntesis para dar algunos antecedentes de la literatura gótica indispensables para entender este género.

De acuerdo con el Diccionario de la Real Academia, la palabra gótica proviene de los Godos, tribus bárbaras que representan el caos y la destrucción. Para José González (2006), se trata de un movimiento literario que surge a finales del siglo XVIII como reacción a la Ilustración y busca la evasión como forma de contrarrestar el conocimiento racionalista. La primera novela gótica fue El castillo de Otranto (1765) de Horace Walpole- que va a ser la base para exaltar los paisajes tenebrosos, ambientes medievales, los castillos, cementerios, los fenómenos paranormales o elementos sobrenaturales. Posteriormente, la tónica de sus personajes está marcada por el suspenso de los hombres vampiros, lobos y la presencia de muertos vivientes.

En el discurso literario de la narrativa gótica hay que mencionar a Mary Shelley (1797-1851) creadora de la novela Frankenstein (1818). Se trata del joven científico, Víctor Frankenstein, quien a través de arduos estudios de biología, química y física logra dar vida a un ser monstruoso compuesto de restos de cadáveres, con una mentalidad asombrosa, fuerza y agilidad descomunal. Víctor rechaza su creación igual que la sociedad. El Monstruo le pide a Víctor que le haga una compañera, de lo contrario su venganza será terrible. Víctor se niega y efectivamente, el Monstruo cumple su promesa. La propuesta del texto es variada: se cuestiona la ética científica y religiosa. Y anticipándose a una relectura de Freud, el hijo busca la desgracia del padre, de su creador: 
aniquila a todo lo que el padre ama y este persigue al monstruo en todos los confines de la tierra. Al fin, en buena ley freudiana, el padre muere y el hijo se pierde entre el hielo del polo Norte y la incertidumbre de la noche.

¿Y cuál es la relación de la novela gótica con el discurso literario costarricense? Se trata de una incursión, una exploración sobre la temática del terror. Hay que destacar que la Editorial Club de Libros ha impulsado la narrativa de terror y ficción (Telarañas, Aquelarre, Poe Siglo XXI y más) En la colección de cuentos "Telarañas", se encuentran los más diversos temas: un narrador protagonista que es devorado por las arañas a placer (La telaraña, de Jacques Sagot); la burla de una pelirroja en la infancia y un suceso en el colegio marcan al protagonista para sentir aversión por ese color. Finalmente, al sentirse calumniado por la hija de su amiga decide realizar un conjuro para ahogar a la niña (El mechón rojo de José Ricardo Chaves); Kobalsky despierta una mañana con la sensación de haber vivido el mismo episodio hace tiempo y para engañar al "déjá vu" asesina a cincuenta personas cuando salen de misa (Déjá vu, de Evelyn Ugalde).

El déjá vu es un concepto clínico creado por el investigador psíquico francés Émile Boirac (1851-1917) y consiste en la sensación de haber vivido o ser testigo de un hecho. En el cuento $L a$ confesión, de Guillermo Fernández, Bernardo cuenta a la joven Manuela su vida de traidor y promete entregarle el pájaro que un indigente le vendió. Bernardo arrastra su pasado de judío y el fantasma que lo acosa -la culpa- del comandante al que le dio todo tipo de información de los suyos. En el cuento Canela y menta de Alejandra Vargas, desfilan los desdoblamientos del que ve su propia muerte y el mejor cuento de esta colección de terror: Praga Night Club de Daniel Garro trata sobre un extraño personaje y sus amigos que son "emboscados" por vampiros que realizan una masacre. Lo destacable del texto es la técnica narrativa, el erotismo literario y el círculo perfecto como cierre narrativo. Atmósfera de suspenso, el misterio que ronda, los fenómenos sobrenaturales, los aparecidos, se recogen en los textos anteriores; pero, sin que ello signifique desmérito, falta esa fuerza telúrica y sobrenatural.

Si la literatura gótica presenta un auge en el contexto costarricense, no menos esplendorosa es la de ciencia ficción. Sin embargo, es necesario repasar brevemente los discursos fundadores. Para algunos estas obras se originan con el mito del hombre con sueños de volar y conocer mundos; otros no dudan en señalar que Dédalo fue el primer viajero del espacio y del laberinto dialéctico que persigue al hombre hasta la eternidad; hay quienes señalan a Luciano de Samosata y su Historia Verdadera, (un ciclón marino arrastra el barco hacia la Luna); ¿quién puede dudar del genio del Renacimiento: Leonardo Da Vinci y su invención de submarinos, automóviles, helicópteros?, y Mary Shelley con su Frankenstein o Edgar Allan Poe La incomparable aventura de un tal Hans Pfaal y muchos más; Julio Verne (De la Tierra a la Luna); H.G. Wells, La máquina del tiempo o Isaac Asimov y tantos más. En el caso de Costa Rica, hay que subrayar que los textos publicados por la UNED (2011) Objeto No Identificado y otros cuentos de ciencia ficción y Posibles Futuros cuentos de ciencia ficción, lo mismo que El fin del mundo cuentos apocalípticos y Poe Siglo XXI (Club de libros, 2010, 2012), son superiores al compendio de cuentos de literatura de ciencia ficción C.R. 2040 (UNED, 1996). El detalle está en el tratamiento del lenguaje y en el desplazamiento de espacios, más que en la temática de viajes al futuro, máquinas inteligentes, genética, redes informáticas.

Una muestra del salto cualitativo de la llamada "literatura de ciencia ficción costarricense" es una selección de cuentos editados por Grupo Nación GN S.A. (2012), los cincos narradores (Iván Molina, Jessica Clark, Daniel Garro, Ericka Lippi y David Díaz) tienen como punto en común el "avance científico". Una tripulación china que llega a Marte y descubre los restos de una nave soviética en cuyo interior hay una astronauta (Molina). Lo destacado del narrador es que sugiere los resabios de la guerra fría y algo más ajustado a lo verosímil: la denuncia de la masculinidad que niega todo protagonismo de la mujer. Esta 
temática acusa a una sociedad "desarrollada", pero enclaustrada en el discurso dominante del machismo. En Ragnarök, Clark alude al intertexto bíblico del bien y el mal: el hijo desafía al padre y reina sobre la tierra y para sorpresa de aquellos descendientes de Adán: la "realidad" subyace o pasa desapercibida. En El vuelo final de Kayla 8, Garro es una nave inteligente, sensible, capaz de burlar todos los sistemas que pretenden destruirla y es tan audaz que destruye las mismas defensas que planeaban su ejecución; sin embargo, la nave sigue flotando en la "realidad" o, más bien, flota de espaldas a la realidad o simplemente es una "realidad virtual". En El impulso necesario para despertar, Lippi es un triángulo "amoroso" en el cual, como suele suceder, el tercero es objeto del deseo de una investigación genética cuyos hijos serán Cyborgs boys (en mi traducción libre: muchachos con organismos cibernéticos). En Los señores de piedra, Díaz es una evocación a un pasado cuya restauración es producto de la intervención de una nave espacial. Dos enemigos irreconciliables: comunistas (Francisco y Felipe) y figueristas (Manrique y Víctor) se enfrentan en el campo de batalla en Pérez Zeledónno obstante, son secuestrados por una nave espacial, ahí tienen que luchar con unos monstruos de piedra;al final, reconocen el valor de cada uno y la nave los regresa a la montaña. El deseo del narrador por cerrar el conflicto choca con una realidad que lo desconoce.

En fin, esta renovación del discurso literario tiene mucha aceptación en un contexto y en una época donde el desencanto se teje y entrecruza con todos los discursos simbólicos de la producción literaria costarricense. El espacio está abonado para que cada poeta, cada escritor, cada ensayista trabaje la palabra, el lenguaje y le saque músculo al discurso literario, como dice el poeta Carlos Calero.

\section{Referencias}

Alvarado, O. (2009). Literatura e identidad costarricense. San José: Euned.

Bonilla, A. (1984). Historia de la literatura costarricense. San José: Stvdivm.

Casasa, L. y otros (2011). Posibles futuros cuentos de ciencia ficción. San José: Euned.

Castillo, M. (2011). Objeto No Identificado y otros cuentos de ciencia ficción. San José: Euned.

Clark, J. y otros (2010). Poe siglo XXI. San José: Club de libros.

Clark, J. y otros (2011). Aquelarre cuentos de ciencia ficción, terror y fantasía. San José: Club de libros.

Cortés, C. (2003). La invención de Costa Rica. San José: ECR.

El Heraldo, 1894.

Enciclopedia del Estudiante (2005). El inicio del siglo XX: las vanguardias. Barcelona: Santillana.

García, J.(1970). El Moto. San José: ECR.

Jiménez, A.(2008). El imposible país de los filósofos. San José: ECR

Jiménez, M. (2005). El Jaúl. San José: ECR.

Molina, I. y otros (2012). Marte inesperado y otros relatos... San José: Grupo Nación.

Molina, I. y otros (2012). El fin del mundo cuentos apocalípticos. San José: Club de libros.

Quesada, A. (2002). Uno y los otros. San José: ECR.

Quesada, A. (2010). Breve historia de la literatura costarricense. San José: ECR.

Rojas, P. y otros (1996). C.R.2040. San José: Euned

Sagot, J. y otros (2011). Telarañas cuentos de terror costarricenses. San José: Club libros.

Schwartz, J. (1991). Las vanguardias latinoamericanas. Madrid: Cátedra.

Solís, P. (2001). El movimiento de vanguardia de Nicaragua. Managua: Fundación Vida.

Soto, R. (2009). Pingüinos, camellos y ornitorrincos sobre literatura y... San José: Euned.

Revista del Registro Nacional. Materia registral (2001). 145 años de historia registral. Año 6 No. 4: 3. 